\title{
What's in a Title? A Cognitive Approach to the Role Played by Translated Text Labels and (Un)adapted Semiotic Elements
}

\author{
Catalina Iliescu \\ University of Alicante \\ iliescu@ua.es
}

\begin{abstract}
This paper draws upon the importance of titles in intercultural communication starting from the results of an experiment in the field of psychology aimed at measuring the mnemonic value of titles as well as the expectations and evaluations they entail or the influential power they exert on receivers. Assuming that translation is a form of communication and adopting an eclectic approach based on the functionalist view in translation and the relevance theory in linguistics, I will try to analyse the role played by text labels in literary communication through an example provided by the title of a translated drama. I will also try to observe how the dichotomic tendency 'informativity versus/and/or motivation' is solved in this case of title translation. In addition, so as to complete the view of an intercultural communicative act of such a complex nature, some semiotic elements accompanying or highlighting the translated title will be discussed within a cognitive-communicative framework.

Therefore, if both titles and semiotic elements function as ostensive stimuli in the literary/dramatic intercultural communication, then a separation between both types of stimuli is needed. Thus, titles will be dealt with as 'linguistic ostensive stimuli', whereas pictures, colours and fonts manifested by the front covers, which are part of the communicative situation since they are meant to introduce the communicative act (i.e. the dramatic text) to an audience, will be dealt with in terms of visual or typographic ostensive stimuli.
\end{abstract}




\section{Introduction}

In order to establish a conceptual scheme for this analysis, we need to define some of the notions to be employed here. To begin with, what is a title to a literary text? A very simplistic definition of the term would say a title is the name of a text. This implies two main characteristics: its shortness and its capacity of encoding information regarding that text. But these qualities do not always prove true since 1) conciseness is relative (it depends on cultures, fashions, genres) and informativity can be systematically infringed by literary trends in which titles' opacity or rupture with the rest of the text is one of the defining principles. On the other hand, when the author resorts to ellipsis or polysemy, meant to increase expressiveness, the title becomes richer in poetic effects but less informative in data linking it to the text.

\section{Theoretical background}

Titles have been studied from several different perspectives. Researchers from the field of the 'theory of title' (also called titrologie) tried to determine whether the label was supposed to be interpreted as part of the text itself or on the contrary, as an independent, paratextual element (see Genette, 1982). Semioticians (see Rothe, 1970, 1985; Hoek, 1981) attempted to explain the relation existing between title and text in terms of a sign referring to another sign (both of a linguistic nature) and tried to determine whether this relation was a singlesense one (from 'label' to 'product') or a bilateral one in which the text evokes the title in turn.

One of the most prominent approaches to text titles is the functionalist one. Attempts to define the notion from this perspective searched for the identification of the primarily significant function (out of the several existing ones) of a given text title. According to Slama-Cazacu (1999: 721) this is a difficult question for the researcher, since titles have no inherent function but are given a function by the sender. In the act of reception the recipients decide which function the title has for them. Our efforts to determine the hierarchy of functions intended for a given text are hampered by the wide range of functions (sometimes overlapping) which may comprise a heraldic one (announcing the text to come), a cryptic one (encoding the text encapsulation to be stored in memory), a summarizing one (offering compressed information of the text), a hermeneutic one (giving a clue for text interpretation), an iconic one (provoking associations with the text contents), or a stimulating one (awakening the interest of the reader in discovering the text).

The hierarchy of title functions bas been studied experimentally by Slama-Cazacu (1991, 1999) who tried to find the dominant processes involved in title creation and perception. According to her, the dominance of one of the processes related to human mental competences depends on the aim pursued by the text under discussion. But what are these processes? According to Guilford they are: 1) knowledge (discovery or recognition), 2) memory (retaining known information), 3) divergent thought (search for solutions to a 
problem) ,4) convergent thought (elaborating information to lead to a correct answer), and 5) evaluation (decisions upon correctness or adequacy).

Slama-Cazacu's position is very similar to the one held by skopos adepts in translation studies (as we will see below in Nord's discussion on titles). By a three-stage experiment (1999: 722) she observes that:

The influence of the title in recalling a whole (even complicated) text is evident. A title which is too general for a given text provokes a loss of accuracy in subjects' capacity to remember the contents.

In 're-naming' texts, subjects tend to produce titles which better correspond to the information contained in the text.

When asked about their opinion on 'a good title', most of the subjects showed that the paramount quality of a title was its motivating capacity, whereas the rest of the subjects equally opted for concision or informativity (understood as the link with the informational contents of the text).

Regarding the negative features of a title, all the subjects coincided in vagueness/overgenerality or exaggerated polysemy as being the main causes of inadequacy.

The conclusion drawn by Slama-Cazacu from such an experiment is that the principle which seems to be essential in title production and reception is based on a dual tendency: the search for an exact and specific correspondence between title and informational contents on the one hand, and the claim for motivation (the capacity of a title to raise the reader's interest and curiosity) on the other.

We will return to this dichotomic tendency observed by Slama-Cazacu but first, let us see in what way cognitive linguistics (more precisely Sperber and Wilson's relevance theory) can help us in this comparative study of a translated title and its semiotic support.

In Translation Studies, Nord (1989, 1993, 1994 and 1995) starts from the assumption that titles and headings are textual units forming a text-type (1989) and finds three aspects which are vital for the translator's work: 1) the communicative functions; 2) the culturespecific and genre-specific ways to verbalize these functions; 3) the culture-specific structural conventions determining the textual design of titles. Adopting the hypothesis that translated texts have to 'function' in the target culture, Nord shows that texts require markers to indicate the intended functions to the target recipients and if these markers are not likely to be recognized, then the translator has to give the necessary clues for the readers to interpret unknown markers. Since titles are considered to be text-types, they are characterized by structural features, literary conventions and inter-textual relationships existing in a particular culture (1995: 262). In this sense, Nord (ibid) argues that: "any translation process has to be preceded by a functional analysis of (a) the situation for which the target text (TT) is intended and (b) the situation in which the source text (ST) is (or was) used as a communicative instrument. Comparing the two situations, the translator is supposed to find out which ST features have to be changed or adapted in order to produce a TT which is apt to serve its purpose". In other words, the translator has to reconcile the 
conditions of functionality prevailing in the target culture with the communicative intentions of the source-title sender. The functions that titles may achieve, according to Nord (1995:265) are six: distinctive (with regard to the culture-specific title corpus to which it belongs), metatextual, (obeying the genre conventions of the culture it is part of), phatic, (attracting the attention of its culture-specific audience); referential, (the information transmitted has to be comprehensible within the culture-specific world-knowledge), expressive (emotional evaluations have to be consistent with the value system of the given culture) and appellative (submitted to the expectations of the prospective readers). By means of an extensive corpus of translated titles, Nord presents a model for functional translation of this text-type also applicable to other kinds of text, but based on the same principles of functionality and loyalty.

Intention, one of the basic components of human communication, is explained by relevance theory (henceforth RT) as a dual concept made up of an informative and a communicative side. According to Sperber and Wilson (1997: 699): "A communicator intentionally engaging in inferential communication perceptibly modifies the physical environment of her audience -that is, she produces a stimulus. She does so with two characteristic intentions the informative intention, to inform the audience of something, and the communicative intention, to inform the audience of her informative intention". From this dual nature of intentions characterizing human communication two emerging concepts (Sperber and Wilson, 1986/95: 58-61) are derived:

Informative intention: the intention to make manifest or more manifest to the audience a certain set of assumptions.

Communicative intention: the intention to make mutually manifest to audience and communicator the communicator's informative intention.

This manifestness of intentions is called ostention in RT and is explained by the fact that the human brain by nature, only pays attention to what is presumably relevant, thus, any request for attention on behalf of the communicator will convey a presumption of relevance. In other words, the communicator draws the hearer's attention to something that is likely (provided the hearer invests enough effort in discovering it) to supply relevant information. As we know, human cognition aims at improving the quantity, quality and organization of the individual's knowledge; it is relevance-oriented. Therefore, by predicting the cognitive environment of an individual, we are able to infer the assumptions that he is likely to entertain. Thus, we get a clue of how his thoughts can be affected if we modify the mutually manifest cognitive environment.

In RT terms, communication is possible in at least two ways: by means of ostensive stimuli, providing the audience with evidence about the communicator's informative intention and by means of a common code shared by communicator and receiver which in fact is used to strengthen ostensive-inferential communication. Ostensive communication is seen by RT as a request for attention through an ostensive stimulus. There may also be 
unintended ostensive communication, as in the example of a yawn intending to indicate the subject's tiredness but failing to look natural (see Sperber and Wilson, 1986/95: 64) and therefore, making the informative intention mutually manifest instead.

What are the requirements of the stimulus (verbal or nonverbal) in ostensive-inferential communication? Sperber and Wilson (ibid.) stated three requirements to be met by ostensive stimuli: a) they must attract the addressee's attention; b) they must channel his attention towards the addresser's intentions; and c) they must reveal the addresser's intentions. Once they are recognized, a guarantee of relevance creates expectations in the hearer by suggesting that the utterance is relevant enough to deserve the hearer's attention. Starting from this definition provided by RT, let us now consider the title of a (literary) text as a stimulus produced by the author who intends either to make manifest (or more manifest) to his audience a set of assumptions (informative intention) or/and to make mutually manifest an intention to inform (communicative intention). Similarly, the semiotic display in which the title is embedded is also an ostensive stimulus produced by the publisher with the same dichotomic intention.

If we move back to Translation, our scheme becomes more complex, since it allows, apart from the author's message (ST), the intervention of more than one translator producing different target versions (TT1, TT2 etc) and certainly several publishers issuing a number of editions (in both source and target cultures).

\section{The case in study}

Since one of the purposes of this paper is to discuss the importance of titles in communication (more precisely in intercultural communication), let us consider the case of a Romanian literary text belonging to the drama genre and its translation into English. My intention is to analyse the title and the visual or typographic elements in the cover of the books in the source and target editions.

First, I will try to compare linguistic ostensive stimuli used by author and translator in the source and target cultures, as well as the degree of strength acquired by the set of communicated assumptions in either case. Also, the dichotomic tendency (informativity versus/and/or motivation) identified by Slama-Cazacu in her experiment will be checked in the case of the drama title considered. Finally, the semiotic elements displayed by the front cover will be also discussed in the same terms.

\section{Linguistic ostensive stimuli in the ST}

The play under observation is one of the exponential texts in new Romanian drama. Its author's original way of tackling history as well as his modern vision upon the creation of myths by means of the interlock of fantastic elements and documentary data, make him one of the most outstanding figures of Romanian literature with a recognized universal 
projection. A treia teapa (The Third Stake) is a historical drama ${ }^{2}$ mixing tragedy and comedy elements with ballad nuances and ruthless irony with folkloric traditions in an unusual structure.

In "Răceala" the action is suggested rather than shown directly. Mohammed the II, Conqueror of Constantinople organises a spectacular military expedition against Vlad Tepeş Prince of Wallachia in 1462 aiming to enthrone Vlad's brother, turco-phile Radu the Handsome. Tepeş(The Impaler) does not appear at all; he is the principal off-stage character, although one can feel his presence all the time through comments on his actions, decisions and obstinate resistance.

On the contrary, "The Third Stake" brings Vlad Tepeş on stage almost all the time, a tragic character bearing an implacable destiny. The playwright gathers, as if in a melting pot (Zamfirescu, 1986:695), the prince's appearance and the different echoes of his deeds as expressed by chronicles, documents of the epoch, folklorical transpositions, anecdotes and legends provoked by his controversial personality.

In the 1980 edition (as well as in the commented republished versions in 1984, 1986) the play is entitled:

A Treia Teapă

Dimineata, la prînz, si seara

(Tragedie populară în cinci acte)

\section{The Third Stake \\ In the morning, at noon and in the evening}

(Folk Tragedy in five acts)

The first contact with the dramatic text is achieved by means of three elements. One is the title which, from a functionalist view, apart from its natural phatic function (it opens the communicative channel establishing a first contact with the reader/spectator), can also play an expressive function, since the notion used has a symbolic value for the Romanian audience, evoking emotions (of a patriotic nature) and appealing to a considerable amount of previous knowledge also called 'initial context' (see Yus Ramos, 1998:307). From a psycholinguistic view, this title engages, apart from cognitive processes (such as perception, thought, reasoning, comprehension, etc) and subjective processes such as evaluation, also a hypothetic process, namely motivation, which comprises internal variables (such as instinct, necessity, aspirations) or external ones, such as the value of a given object ${ }^{3}$. In our case, from the very first contact with the title, a Romanian reader would think of one singular outstanding historical figure. If we take the above mentioned dichotomy of intentions proposed by relevance theory (informative/communicative), the amount of informative intention contained in this three-element label (title, subtitle, genre distinction) seems to prevail is strongly manifested by means of the term 'stake' directly linked to a historical figure in the Romanian national consciousness, Vlad Dracul, known as 'Tepeş' (The Impaler) a surname related to his favourite punishment and derived (half a century 
after his death) form 'teapā' (stake) by means of a common anthroponimic suffix 'eş' (see Gutjia, 1976:15).

In the Romanian versions of the play, apart from the title, there are two more labels worth mentioning. One of them, "Dimineaţa, la prînz şi seara" (In the morning, at noon and in the evening) apparently indicates the three moments which make up the chronogram of the dramatic conflict (these moments mark the opening of each act). But in fact Sorescu uses this subtitle as an ironical device to parody certain style in proletarian aesthetics, very common for the period in which the play was written. It is a cliché borrowed from the medical jargon (expressing a mode of administrating medicines) and it characterizes the so called 'wooden language' of which the main feature is the repetition of fossilized structures together with: an exaggerated substantivization, lack of deixis, passive and impersonal constructions or the use of imperatives (for a more extensive discussion on "wooden language' strategies, see also Stamatoiu, 1995; Thom, 1993). Romanian readers would recognize this formula and detect its parodic function.

Finally, the third label borne by this play (apart from title and subtitle) is a typological (or classificatory) text which announces that the text belongs to the dramatic genre and particularly to a style that combines folklorical epics with tragedy. In Gutt's (1991)view this kind of label has the pragmatic function of increasing relevance (by saving mental effort) since it guides the audience towards the intended interpretation. The processing cost is reduced since the audience know what they are supposed to find beyond them. By calling it a 'tragedy' Sorescu counteracts the tone of parody adopted by the subtitle "dimineaţa, la prinz şi seara", reminding the reader that a play dealing with such transcendental historical facts as those that occurred during the reign of Vlad Tepes cannot be taken frivolously. Therefore, by means of the third label, Sorescu re-establishes the balance through a formula that combines the prevision of tragical events with the folk involvement promise. By adding the adjective 'populară' to the noun 'tragedy', Sorescu somehow softens the expectation of hardness and a certain feeling of relief permeates.

Let us now summarize the observations gathered so far. As ostensive stimuli, title, subtitle and genre classification label contribute to relevance increase in several directions. First, by introducing the word 'stake' in the title, certain information is forwarded, and the bistorical reference is assured, hence the informative intention of the title. On the other hand, the second label displayed by the subtitle suggests a parodic tone which reveals an intention to ease the tension but also to criticize. The same duality can be found throughout the play, bence the informative intention of the subtitle. As I showed elsewhere ${ }^{4}$, the classification of the dramatic text as a 'folk tragedy' draws the audience's attention not only to the protagonist's tragic destiny but also to the presence of the other great hero of the play who is, as Sorescu says, 'the common folk'. When a Romanian receiver reads 'Tragedie populară' he is effortlessly supposed to understand what kind of characters are expected to sustain the plot, hence the informative intention of the classificatory label.

If we observe now the three conditions stated by Sperber and Wilson in relation to the 'ostensive stimuli', we see that in general they are fulfilled: The title (a) attracts the receiver's attention by means of a key term like 'stake' and a symbolic number such as 
'three'; (b) reveals the underlying intention, and (c) focuses the addressee's attention towards Sorescu's communicative intention (he wants to call the audience's attention) and informative intention (he wants to inform the reader of the topic dealt with in his play).

The subtitle (a) attracts the reader's attention and curiosity through the clash it produces with the title and through the peculiarity of its contents; (b) reveals the underlying intention, (c) it channels the addressee's attention towards Sorescu's intention of introducing a humorous clue through the 'wooden language' parody.

The classificatory label (a) attracts the reader's attention by the uncommon genre proposed (folk tragedy); (b) reveals the underlying intention, (c) it channels the reader's attention towards the intention of mitigating the harshness of tragedy by qualifying it as 'populară'.

A first conclusion that can be drawn here is that the linguistic ostensive stimuli under discussion (title, subtitle, classificatory or text-type label) bear both a communicative intention and an informative one.

Returning to Slama-Cazacu's experiment and her conclusion claiming there is a dual tendency in title creation towards motivation and/or informativity, our observations regarding the title in the ST are the following:

a) the motivation is assured by the author's name (who was very popular at that moment and still is after his death) and by the term 'stake' invoking one of the most controversial figures in the nation's history. As well, the motivation might be achieved through the parodical clue contained by the subtitle.

b) informativity is guaranteed again by the term 'stake' with all its implications (shown above) and by the text-type label 'tragedie populară' which informs the audience of the tragic fate of the main character and of the presence of another constant element in Romanian literature, the folk.

\section{Linguistic ostensive stimuli in the TT}

Let us now see to what extent these linguistic ostensive stimuli are preserved in the English translation of the play published by Forest Books (London, Boston) in 1987 and reprinted in 1990 with no modifications (except for the colours on the front cover). The front cover displays the title preceded by the author's name and a clear affiliation to the dramatic genre through the text typological label 'a play by', whose function is distinctive (Nord, 1995: 264). There is also mention that this is a translated text. The first thing to be noted in the English title is the absence of the associative clue ('stake' automatically links to Vlad in any Romanian reader's mind). The numeric notion which is not haphazardly chosen by Sorescu (' 3 ' is a fatidic number in the source culture), also disappears. The third stake symbolizes Vlad's spirit of justice. It is a spare stake awaiting for one extreme sacrifice which is 
eventually committed by the Prince in his obstinate wish to distribute justice to everyone, even to himself.

Why does the English version avoid the word 'stake'? The translator's difficulty in preserving it , is double: 1) the Romanian word and its English equivalent do not refer to the same object; 2) the word 'stake' has additional connotations in English. Firstly, the term 'stake' makes a direct and precise reference in the source culture to a medieval punishment since its first meaning in the DEX (1996), DEI (1999), MDE (1978) is "long and pointed post used as an execution instrument in the past"; whereas in English, 'stake' is (1) "a pointed piece of wood, metal, etc, for driving into the ground as a mark, for holding a rope, etc". (2) "(in former times) a post to which a person was tied for being killed, especially by burning" (Longman-Language and Culture, 1993) or (1) "a stick or metal bar driven into the ground as a marker, part of a fence, support for a plant, etc"; (3) "a method for the practice of executing a person by binding him to a stake in the centre of a pile of wood that is then set on fire" (Collins, 1986). On the other hand, 'stake' is also the instrument associated with the death of the vampire in a certain sector of literature and film production which, of course, influence readership in general.

Obviously, the English version title belongs to the translator, but the decision whether the play/book is edited under that name, or whether the rest of the ostensive stimuli (either linguistic or semiotic) are going to be maintained and in which shape, is not among the translator's responsibilities but a publisher's concern. Quite often, problems may arise between the commissioner's (publisher's) idea of the best translation strategy for a given title, which is very likely to be submitted to the appellative function (in Nord's classification, 1995) and the translator's idea on the information to be conveyed.

Therefore, when we talk about translated ostensive stimuli of literary texts and try to analyse, as in this case the linguistic stimuli (title, subtitle, classificatory or text-type labels) we cannot refer to a single intentionality as we do when discussing the source text whose author is generally responsible for labelling it. In the case of translation there are at least two intentionalities involved: that of the translator (who wants the TT to be functionally loyal, in terms of Nord) and that of the publisher (who wants the TT to be optimally functional for "the intended skopos and recipients", see Vermeer, 1998:50).

In this case, the translator's intention is to break with the commercial explotation of the character, to draw a dividing line between the Romanian historical myth of Vlad Țepeş as a positive hero (cruel but fair) and the terrifying (but also attractive) figure of Dracula, the gothic character. The translator, who is a historian and analyst of recent Romanian history and political life, in fact warns the reader (see the 'Introduction' to the volume 1987: 14) about the fact that "[t]here is no suggestion here of Bram Stoker's un-dead vampire Dracula or of a quest to conquer eternity -features of the Dracula legend which explain its continued popular appeal".

We have referred so far to title creation and reception in literary communication but the situation becomes more complex in the particular case of theatre. The title must be powerfully persuasive in order to represent not only the written text but also its production. It has to have enough personality to stand on a book cover and on a theatre bill. Following 
Nord's (1995: 265) classification of title functions, we can say that the Romanian title recalls (expressive function) Vlad Tepeş and his sense of justice awakening a patriotic feeling, whereas the English version opts for a title which states the name of the main character of the play trying to maintain the reference to the stake (informative function in Romanian) not by means of the lexical unit itself (since the semantic features are different as we have shown above), but contained in the Prince's nickname 'The Impaler' recalling the punishment instead of referring to the instrument, so the referential or informative function is maintained. On the other hand, by using the name 'Vlad the Impaler' which clearly brings to mind the medieval hero, the translator is faithful to the source culture feeling (where the name Dracula has negative, offensive connotations) through an avoidance strategy, but at the same time he has to be loyal to his target audience who might not recognize the character unless Stoker's referent is inserted. So the expressive function of stake in the original is played here by the name Dracula. Thus, the translator optimizes relevance showing the audience the shortest inferential path to Vlad Tepess, otherwise hindered by the lack of popularity of the historic figure in comparison to the vampire.

If we go back to Slama-Cazacu and the dichotomic tendency she states as a result of her experimental study, we see the informativity as well as the motivation are preserved by the English title. Starting from this title, the English audience can soon process the information, presumably with no additional effort, associating the Transylvanian vampire with the Wallachian ruler, and inferring that the play is about the latter (otherwise, the nickname would make no sense), whereas the presence of Dracula is just a key for a quick identification. Perhaps, the resonance of the name Stoker added to the Impaler's legend, has contributed to the publisher's approval of this title on grounds of its appelative function.

As far as the subtitle is concerned, (Dimineaţa, la prînz şi seara), which appears in the three Romanian editions $(1980,1984,1986)$ the translator opted for omitting it presumably due to the low probability of reproducing the informative intention in the ST. Still it would have transferred the communicative intention but the translator and publisher probably thought this element would only puzzle the target audience. So that the parodic nuance could have been detected, the formulaic subtitle would have needed a greater amount of shared knowledge between translator and his audience, similar to that existing between the author and his readers who are aware of the fact that Sorescu is a controversial figure in Romanian literature who utters transcendental truths wrapped up in simple, everyday stories. .

The tone Sorescu uses to tell us the story of his tragical hero is playful. Literary criticism has often pointed out a certain acceptance of fate and a strange dualism of Romanian spirituality which lead people to make fun of their own misery. This duality of tragic and humorous elements is present also on the level of ostensive stimuli we are analysing. The playful tone in the subtitle is counteracted by the genre classification in the original as 'tragedy', which in turn is softened by the presence of the 'folk' reference. Once the translator decided to omit the subtitle, he would have bad to somehow keep the oxymoronic nature of the labels meant to establish the first contact with the audience. $\mathrm{He}$ is however forced to eliminate this label too, probably due to publishing conventions. 
The title still conveys an informative intention although the set of assumptions that the English reader derives from a title like "Vlad Dracula the Impaler" is different from that captured by the Romanian reader/audience when perceiving a title like "The Third Stake". Yet the informative intention is preserved (only through different strategies). The front cover exhibits three labels which are different from the original ones:

1) The classificatory or text-type label (A play by Marin Sorescu).

2) The new title (Vlad Dracula The Impaler).

3) The second classificatory label (Translated by Dennis Deletant).

As we have seen, the subtitle was eliminated and the text-type label is slightly different. Instead of the mention "Folk Tragedy in five acts" of the ST, we find a far more general classification claiming the drama genre without any other specification ("a play by ..."). Finally we are informed that the product we are dealing with is a translation which we regard as the second classification of the text. These modifications in the TT imply an alteration of the intention manifested by the ST.

Let us now verify whether the ostensive stimuli in the TT fulfil the requirements stated by Sperber and Wilson which were mentioned previously in this essay.

The title (a) attracts the reader's attention through the resonance of the name 'Dracula' but without raising too many expectations in those who are adepts of the gothic myth (also due to several semiotic elements to be discussed); (b) reveals the underlying intention; and (c) it channels the reader's attention towards the translator's (and publisher's) informative intention (i.e. the play will develop around this main character). The fact that the historical figure's name is used, informs the readership of the point of view adopted by the dramatic text.

The two classificatory labels (a) attract the addressee's attention, although not as much as the title does; (b) focus it on the underlying intention; and (c) they channel the audience's attention towards the publisher's communicative intention; in other words they announce through conventions already established by the target culture that there are two entities (a sender and a mediator) who wish to inform the audience of a set of assumptions contained in the text to follow.

\section{The 'translation' of semiotic elements}

As I said at the beginning of this paper, a complete view on an intercultural communicative act of these characteristics cannot be obtained without a short review of the semiotic elements acting as ostensive stimuli together with the text labels analysed so far. In this sense, there is a striking difference between the English translation of the play and the three Romanian editions regarding the semiotic elements which accompany titles in the presentation of this dramatic text. 
The semiotic elements I intend to discuss are those exhibited by the front cover of each volume and my purpose is to determine which of the signs acting as ostensive stimuli (those joining the ST. or those joining the TT) are more likely to provoke strongly communicated assumptions in their addressees.

One of the most popular sign typologies is given by Peirce (cited in Elam, 1980: 19-31) who identifies three kinds of relations making up this concept: $i c o n$ (relation of similitude), index (cause-effect relation) and symbol (conventional association of ideas).

\section{Visual/Typographic stimuli in ST1}

The front cover of the volume entitled "Teatru" displays no pictures used as semiotic ostensive stimuli; in turn, a striking combination of colours attracts the reader's attention. On a light-grey background, the volume title (in orange) and the author's name (in black) are clearly intended to act as visual stimuli. Regarding the fonts employed, both are very clear (Sorescu's name adopts a style which seems to belong to the Mumbo Black family, whereas the title is written in Cooper Black) and concentrate enough amount of colour to be identified as two separate, even contrasting spots on the page.

Do the ostensive stimuli fulfil the conditions stated by Sperber and Wilson? Apparently they do; both colours and fonts (a) attract the receiver's attention; (b) focus it on the underlying intention; and (c) channel it to the publisher's communicative intention.

\section{Visual/typographic stimuli in ST2}

The volume entitled "Exit through the sky" devoted entirely to Marin Sorescu belongs to a "Commented Theatre" collection. Unlike the previous one, this volume displays a more visible intentionality, since the ostensive stimuli (pictures, colours and fonts) seem to play a more prominent role in this volume.

1) Regarding the pictorial signs displayed by the cover, we can mention a composition made up of a bicoloured vertical rectangle in the central upper part of the page and a smaller, one-colour, vertical rectangle on the bottom, still central. As the composition plays with two nuances of blue, when perceiving the picture together with the title (which mentions the word 'sky'), we might consider the image as a foregrounding device since it reinforces through a visual stimulus the idea expressed linguistically. The rectangle can be understood as a symbol for the sky on grounds of the associative power of its colour, but it only functions in the presence of the title, so the linguistic element seems to be the most important part of the stimulus.

2) The fonts used by the publisher for this cover are varied: for the author's name, written in lower case, a font belonging to the Mumbo Black is chosen (the same as in the 
previous volume), while the title characters are totally different since a Stop $D$ font type is preferred which makes it almost illegible. It is obvious that the intention was to focus the receiver's attention on the author's name and not on the title. In turn, the fonts used for the collection and publisher's names are more common (belonging to the Cooper Black family and Futura respectively).

As we have seen, the semiotic stimuli of this cover are not very powerful, although there are a couple of foregrounding devices probably intended to raise the reader's interest in the author's name (at that time Sorescu was at one of his best literary moments). The communicative intention seems to prevail in this volume too, by means of the ostensive stimuli, except maybe for an attempt to inform (through the picture discussed above). In my opinion, the three conditions stated by Sperber and Wilson are met by these stimuli in the sense that (a) they attract the receiver's attention through the colour contrast and fonts for the author's name and through the abstract picture; (b) focus it on the underlying intention; and (c) they channel the addressee's attention towards the informative intention (through the legibility of the author's name and illegibility of the title).

\section{Semiotic ostensive stimuli in ST3}

The "Anthology of Historical Drama" scarcely contains any visual/typographic elements on its cover. No pictures are shown and no combination of colours attracts our attention. The fonts used for the title (written in capital letters) belong to a common type (Times New Roman) and their colour (dark green on a cream background) make them easily distinguishable. The same fonts are used for the subtitle (specification of the period comprehended by the anthology -Times New Roman lower case) and the editor's name in capital letters again, only of a smaller size than the title. Finally, on the bottom, the publisher appears (again in Times New Roman characters) and with a considerably reduced size.

As we have seen, this volume shows no visible attempt to make an intention manifest through ostensive stimuli and this attitude might be due to a general norm of the polysystem (in Even-Zohar's terms). Such types of publications like anthologies (regarded as manuals or reference books) were not marketed in Romania but simply brought out. A reduced amount of marketing strategies was employed in the case of other genres (such as art or children literature); however, attempts to raise interest or expectation through visual or typographic channels and through foregrounding certain information were scarce on a socialist market where publications were planned and financed by the state and the low price was their best publicity.

This cover displays a limited number of stimuli which convey, again, an informative intention. The ostensive stimuli hardly fulfil their conditions: they do not attract the addressee's attention, but do convey (through a very low number of devices) the publisher's informative intention. 


\section{Semiotic ostensive stimuli in the TT}

Unlike the three Romanian volumes, the front cover of the English translation of the play in discussion seems to offer quite a few examples of visual/typographic ostensive stimuli. Regarding the three elements to be discussed in this part of the essay (pictures, colours and fonts), we have observed the following:

1) There are several pictorial signs such as the portrait, the skulls, the stakes and the architectural elements. The skulls play (according to Pierce's classification above mentioned) an indexical role, since they stand for an 'cause-effect' relationship, representing the proof and the result of a policy based on implacable punishment. The stakes which can be made out on the background play an indexical role too as impaling instruments.

The portrait might be seen as an icon since it establishes a similarity with the historical figure of Vlad. A considerable amount of inter-textuality supports this claim, since the portrait (in oil, dating from the $15^{\text {th }}$ Century and preserved in the Castle of Ambras, province of Tyrol), is reproduced in encyclopaedias and history books showing the most emblematic image of Vlad the Impaler, as a medieval prince of Wallachia. The presence of the portrait might be also interpreted as a symbol since it is meant as an association with the historical figure (even for those who haven't seen it before), rejecting the vampire's image, certainly more popular.

The position of the portrait on the cover responds to a foregrounding device since it occupies the central lower half of the page, located just under the title (which happens to coincide with the main character's name), so for any addressee the relation nameportrait is clear and on the other hand exclusive concerning the gothic myth.

The architectural elements displayed on the cover of the English version reveal a detail of the upper part of a traditional Romanian façade containing five stylized arches confined at both ends by narrow columns, ending up in unadorned capitals reminiscent of the Doric austerity. The arches might be inspired by the porch of the traditional Wallachian house or by the Romanian architectural style par excellence, the 'brâncovenesc' born in a later period, a style which combines Baroque and Oriental features with local tradition. The reason why the columns are architecturally too narrow and unadorned is that they stand for stakes, one more foregrounding device for the idea of execution and death.

On the other hand, if we interpret the arches as niches (since each contains a skull) we find that the same indexicality (cause-effect relationship) appears. But in general terms, no matter the interpretation we opt for regarding the architectural elements, one aspect must be mentioned: this architecture is typical of Wallachia, so the cover designer chose to avoid the idea of Transylvania (directly linked to Stoker). The architectural elements can be seen as an icon (establishing a relation of similarity with the landscape that characterizes the region where the action is taking place), or as an index (if we see the columns as stakes, according to the explanation above). 
2) The second element to be analysed as a foregrounding device is the use of colours. An interesting aspect worth mentioning here is the fact that the publisher decided to change the coloured portrait of Vlad The Impaler (from the first edition -1987) to a black and white one for the reprinted edition (1990). The result is a more striking image of the character due to a better contrast. The red colour for the title placed in the central part of the cover seems to be a symbol since it immediately triggers an association with the idea of blood.

3) The third element to be discussed as a foregrounding device are the fonts, i.e. the shape in which linguistic elements appear on the cover. Both classificatory levels (genre/author and modality/translator) are displayed in a very accessible manner. The style is clear, spaced out and the letters are white on a dark background. The title, as I said, is written in red and the fonts used in this case seem to be Americana, a style characterized by letters partially thicker, so in our case, concentrating more amount of red, presumably in order to cause an impact on the reader who is very likely to memorize the whole composition easily.

It goes without saying that the semiotic ostensive stimuli displayed by the English version of the play convey both an informative and a communicative intention through the elements and devices discussed above. The ostensive stimuli meet the three conditions since they attract the addressee's attention through the use of emblematic pictures, striking colours and friendly fonts and they strongly convey the informative intention, making manifest certain assumptions (the historic figure and not the gothic myth is dealt with in the play).

\section{Conclusions}

In this essay I have tried to analyse from a cognitive point of view the way in which the linguistic (title, subtitle, classificatory label) and visual/typographic (pictures, colours and fonts) ostensive stimuli employed by author and publisher to introduce to a source audience a certain theatrical text were preserved or reproduced in the target product. I also attempted to verify to what extent the dichotomic tendency argued by Slama-Cazacu (motivation versus/and/or informativity) becomes manifest in source and target titles.

This paper sought to show that in one specific case under observation (i.e. a particular Romanian play and one of its translations into English), linguistic and visual/typographic stimuli suffered modifications intended to assure relevance in the target culture. Since ostensive stimuli are essential for the reception of literary texts both in source and target contexts, they are very likely to become the object of an ample comparative study, regardless of the content of the dramatic discourse, maybe with plays from several periods and by different authors translated into more than one version/language and embedded in a more general frame together with other parameters, but the observations drawn from such an approach might throw light on the way in which the principle of relevance influences the 
translator's/publisher's decision-making process intervening in the adoption of one strategy or another in the selection of linguistic or semiotic ostensive stimuli intended to introduce the target product to the target audience.

\section{Notes}

1. This classification of mental competences belongs to Guilford's Personality, 1959 cited in Tyler, 1984: 98; a complementary classification is given (ibid: 99) according to the contents or material available for these operations, bringing out four types of competences: figurative (volumes, shapes, colours), symbolic (letters, digits), semantic (verbal significations or ideas) and behavioural (various social situations).

2. The play was first published in episodes in several literary journals, then staged at the Casandra Theatre (Bucharest) in premiere in 1978, and finally published in a volume in 1980 together with "Rāceala" $(A$ Cold) . It was republished in 1984 and in 1986 in volumes belonging to commented collections. Other productions took place all over the country and today, after more than twenty years it is still successfully performed in many Romanian theatres.

3. Franz Jürgen Blumenberg and Helmut Kury, Herder Lexicon. Psychologie, Verlag Herger KG, Freiburg, 1975.

4. The Relevance of Metatextual Elements in Marin Sorescu's A treia teapă; forthcoming in CETRA.

5. The fonts names have been borrowed from the "Corel Corporation" manuals.

\section{Works Cited}

Elam, Keir (1980): The Semiotics of Theatre and Drama. London: Methuen.

Genette, Gérard (1982): Palimpsestes: La littérature au second degré. Paris: Seuil. . (1987): "Praguri". România literarã 35.

Gutia, Ioan (1976): Storia del nome Dracula. Biblioteca di cultura 87. Rome: Bulzoni.

Gutt, E. A. (1991): Translation and Relevance. Oxford: Blackwell.

Halliday, M.A.K. (1973): Explorations in the Functions of Language. London: Arnold.

Hoek, Leo H. (1981): La marque du titre: Dispositifs sémiotiques d'une pratique textuelle. La Haye/Paris/New York: Mouton.

Nord, Christiane. (1989): "Der Titel -ein Mittel zum Text?: Überlegungen zu Status und Funktionen des Titels". In N. Reiter, ed., Sperchen und Hören: Akten des 23. Linguistischen Kolloquiums in Berlin. Tübingen: Niemeyer, 519-528.

(1993): Einführung in das funktionale Übersetzen: Am Beispiel von Titeln und Überschriften. Tübingen: Francke.

(1994): "Translation as a Process of Linguistic and Cultural Adaptation". In C. Dollerup and A. Lindegaards, eds., Teaching Translation and Interpreting 2: Insights, Aims, Visions. Amsterdam/Philadelphia: John Benjamins, 59-67.

. (1995): "Text-Functions in Translation: Titles and Headings as a Case in Point". Target, 7(2): 261-284.

Rothe, Arnold (1970): Der Doppeltitel: Zu Form und Geschichte einer literarischen Konvention. Wiesbaden: Verlag der Akademie der Wissenschaften und der Literatur in Mainz i. Komm. . (1985): "O convenţie literară-titlul". România literară 33 (1, 2-3, 64-69, 53-58, 47-52). 
. (1986): Der literarische Titel: Funktionen, Formen, Geschichte. Frankfurt a.M.: Klostermann.

Slama-Cazacu, Tatiana (1999): Psiholingvistica: O ştiinţă a comunicăriit. Bucureşti: All Educational.

(1991): "The title of a text: Its fundamental role in improving text construction and reading". In Slama-Cazacu, ed., Psycholinguistics contribution to improved communication Some new issues. Proc. of the Third Symposium of the AILA Commission of Psycholinguistics. Roma: Bulzoni.

Sorescu, Marin (1980): Treatru: Răceala. A treia Teapă.Craiova: Scrisul Romānesc. (1984): Ie şirea prin cer. Bucure şti: Editura Eminescu.

(1987): Vlad Dracula The Impaler. Translated by Dennis Deletant. London/Boston: Forest Books.

Sperber, Dan and Deidre Wilson (1986): Relevance: Communication and cognition (2 ${ }^{\text {nd }}$ edition: 1995). Oxford: Blackwell.

. (1987): "Précis of Relevance: Communication and Cognition". Behavioral and Brain Sciences 10: 697-754.

Stamatoiu, Cristian (1995): Cariul din "Limba de Lemn". Târgu-Mureş: Tipomur.

Thom, Françoise (1993): Limba de Lemn. Bucureşti: Humanitas.

Tyler, Leona E. (1984): Psicología de las diferencias humanas. Madrid: Marova.

Yus Ramos, Francisco (1998): "A decade of relevance theory". Journal of Pragmatics 30: 305 345.

Zamfirescu, Ion (1986): O antologie a dramei istorice româneşti. Bucureşti: Eminescu. 